\title{
La lectura latinoamericana de Hannah Arendt en los escritos tempranos de Norbert Lechner (1970-1984)
}

\author{
Antonio Camou,* Anabella Di Pego**
}

Perfiles Latinoamericanos

Flacso México

\section{Resumen}

La década que va del golpe militar en Chile (1973) a la recuperación democrática en Argentina (1983) dibuja simbólicamente un amplio territorio de nuevas visiones políticas entre los sectores “progresistas" latinoamericanos. Durante esos años la idea de "revolución” fue perdiendo terreno frente a una renovada estimación de las virtudes de la democracia como eje del campo político. Estas notas se concentran en analizar la inspiradora lectura de Hannah Arendt que Norbert Lechner introduce en el debate latinoamericano sobre la democratización. Nuestra hipótesis señala que Lechner mantuvo un diálogo crítico permanente con el pensamiento alemán clásico y contemporáneo. En particular, la apropiación, adaptación y recreación de la obra de Arendt fue fundamental en tres planos. En el plano discursivo, Lechner recrea elementos de la visión arendtiana de la política que le permiten entenderla como una actividad humana intrínsecamente conflictiva y plural. En el plano político-institucional ambos autores desarrollan un registro reflexivo a medio camino entre la filosofía, las ciencias sociales y la literatura. Por último, en la dimensión socioprofesional, la figura arendtiana le ofrece a Lechner un modelo sugerente de intelectual autónomo por oposición al intelectual "orgánico", pero también al experto "neutral".

\begin{abstract}
The decade that goes from the military coup in Chile (1973) to the democratic recovery in Argentina (1983) draws symbolically a broad territory of new political visions between the "progressive" sectors in Latin American. During those years the idea of "revolution" was losing ground facing a renewed estimate of the virtues of the democracy as axis of the political field. These notes concentrate on analyzing the suggestive reading of Hannah Arendt introduced by Norbert Lechner in Latin American debate on democratization. Our hypothesis says that Lechner maintained a critical permanent dialogue with the German classical and contemporary thought. In particular, the appropriation, adaptation and recreation of Arendt's work, was fundamental in three planes. At the discursive level, Lechner recreates elements of Arendt's vision of politics, allowing understanding it as a human activity inherently conflictual and plural. At the institutional level, both authors develop a reflective record halfway between philosophy, social sciences and literature. Finally, at the socio-professional dimension, Lechner finds in Arendt's figure a promising model of autonomous intellectual, as opposed to the "organic" intellectual, and to the "neutral" expert.
\end{abstract}

Palabras clave: Lechner, Arendt, democracia, política, pluralidad.

Keywords: Lechner, Arendt, democracy, politics, plurality.

* Doctor en Ciencias Sociales, por la Flacso México. Profesor investigador del Instituto de Investigaciones en Humanidades y Ciencias Sociales (IdihCs), de la Universidad Nacional de La Plata (UNLP) (Argentina).

** Doctora en Filosofía (UNLP). Investigadora CONICET, con lugar de trabajo en el IdiHCs y docente de filosofía contemporána de la Facultad de Humanidades y Ciencias de la Educación (UNLP) (Argentina). 
Yo destaco dos autores que leo inmediatamente después del golpe: Gramsci y $\mathrm{La}$ condición humana de Hannah Arendt. No sólo por su contenido, también por su estilo de exposición, son textos que incitan a buscar un nuevo marco de referencia

LECHNER (2004)

Si en realidad "provengo de» alguna parte, es de la filosofía alemana

Hannah Arendt, carta a G. Scholem (1963)

a década que se abre entre el golpe militar perpetrado en Chile por el general Pinochet (1973) y la elección del doctor Alfonsín como presidente constitucional de la Argentina (1983), dibuja simbólicamente un vasto y heterogéneo territorio de búsquedas y nuevas definiciones políticas. En particular, para muchos intelectuales del llamado campo "progresista", este periodo - cuyos límites cronológicos hay que leer con generosa ambigüedad - entreteje un recorrido de experiencias vitales traumáticas junto con un itinerario reflexivo, autocrítico y renovador del pensamiento político latinoamericano en torno a la democracia. Así, durante esos años la idea de "revolución" fue perdiendo terreno para dar lugar a una renovada estimación de las virtudes institucionales de la democracia como eje constitutivo de reglas, principios y valores para pensar la política y para actuar en el ámbito público (Lechner, 1984). ${ }^{1}$

Estas notas, que forman parte de un proyecto más amplio, se concentran en analizar la sugerente lectura de Hannah Arendt que Norbert Lechner introduce en el debate latinoamericano sobre la democratización. El enfoque teórico del proyecto asume que al interior de un "espacio controversial" la "refocalización” de la cuestión democrática permitió redefinir la concepción misma de la política (Nudler, 2009). ${ }^{2}$ Esta reorientación estuvo ligada a transformaciones operadas al nivel presuposicional del tejido discursivo básico sobre el mundo social (Alexander, 1989). Entre estos cambios cabe mencionar: una visión del conflicto más flexible y matizada que la definida por el rígido algoritmo de la

1 Un análisis de la bibliografía sobre esta discusión en Camou (2013).

2 Entenderemos por espacio controversial un conjunto articulado de disputas organizadas en torno a un foco y basadas en una serie de presupuestos que forman un terreno común de debate (common ground). Por refocalización haremos referencia al proceso por el cual "los presupuestos básicos de un espacio controversial son sacados a la luz y sometidos a discusión”, lo que implica el "desplazamiento de esos presupuestos desde el common ground hacia el foco” (Nudler, 2009: p. 43). 
"contradicción dialéctica"; una noción de sociedad abierta a diversas zonas de conflictividad plural (etnias, género, minorías sexuales, etc.), reluctante a ser pensada a través de la contradicción capital-trabajo o en el marco del consenso normativo parsoniano, y, finalmente, una manera de entender la identidad de los actores sociopolíticos constituida a través de la interacción, rechazando formas predeterminadas de identificación a nivel socioeconómico o cultural. Las fuentes de la investigación se nutren tanto de un conjunto de textos que constituyeron hitos en el debate democratizador, como de una serie de entrevistas originales a destacados científicos sociales de la región. ${ }^{3}$

En la primera sección presentamos una periodización tentativa de la obra de Lechner que — lejos de un rígido esquematismo—-permite ubicar nuestro análisis en los trabajos elaborados entre fines de los setenta y principios de los ochenta. La segunda sección desarrolla el núcleo de nuestra contribución. La hipótesis que adelantamos de manera exploratoria afirma que, más allá de su opción vital y política por América Latina, Lechner mantuvo un diálogo crítico permanente con el pensamiento alemán clásico (de Kant a Marx) y contemporáneo. En particular, en el tránsito que va de una reflexión anclada en la "revolución" a una visión política centrada en la "democracia”, fue fundamental la apropiación, adaptación y recreación de la obra de Arendt. Esta lectura se manifiesta en los tres planos que — según Wallerstein (1999)— sirven de ejes articuladores en la producción del conocimiento social: en el plano discursivo, Lechner recrea elementos de la visión arendtiana de la política que, a la vez que le permite tomar distancia crítica del marxismo, le posibilita entenderla como una actividad humana intrínsecamente conflictiva y plural, pero sin reducirla al marco de análisis dominado por el cálculo estratégico (elección racional); en el plano político-institucional pueden trazarse significativos paralelos sobre un registro reflexivo y creativo común a ambos autores, a medio camino entre la filosofía, las ciencias sociales e incluso la literatura, y por último, en la dimensión socio-profesional, la figura arendtiana le ofrece a Lechner un modelo sugerente de intervención intelectual autónomo por oposición al intelectual "orgánico"(que primó en distintos sectores de la izquierda latinoamericana entre los ańos sesenta y setenta), pero también con referencia al experto "neutral" (como comenzará a prevalecer en ciertos segmentos académicos del Chile dictatorial e incluso democrático). La tercera sección cierra el trabajo con algunas reflexiones finales que señalan posibles líneas de indagación.

3 Una estancia en el Instituto Ibero-Americano de Berlín nos permitió acceder a la tesis doctoral de Lechner. Agradecemos a sus autoridades y a todo el personal, en particular a Peter Birle, por el apoyo brindado. 


\section{Reflexiones en tiempos de oscuridad}

Norbert Lechner nació en Karlsruhe, Alemania, en 1939. Durante la guerra vive en España y Portugal, y de regreso a Alemania completa su educación básica. Estudia derecho y ciencia política en München, París y Freiburg. Culmina su licenciatura en Derecho en 1964 y se inscribe al doctorado en Ciencia Política. En Freiburg se incorpora al Centro de Estudios del Tercer Mundo, perteneciente al Arnold Bergstraesser-Institut. En 1965 viaja por primera vez a América Latina (Brasil, Argentina y Chile), donde permanece algunos meses. Su proyecto de tesis inicial (sobre la reforma universitaria en Chile) deriva finalmente en un estudio del proceso de democratización chileno. Regresa a Chile entre 1966 y 1967 (con un cargo en la Fundación Adenauer acompañando a Franz Hinkelammert), mientras trabaja en la elaboración de su tesis, y se doctora en Ciencia Política en Freiburg en 1969 bajo la dirección de Dieter Oberndörfer. Luego parte nuevamente hacia Chile donde fijará su residencia definitiva.

Entre 1970 y 1973 fue profesor-investigador del Centro de Estudios de la Realidad Nacional (CEREN), de la Universidad Católica. Luego del golpe de Pinochet una invitación de Jürgen Habermas le permite durante unos meses realizar una estancia de investigación en el Instituto Max Plank, en Starnberg. Posteriormente regresa a Chile para incorporarse como profesor-investigador de la Flacso entre 1974 y 1994, organismo del que también será director. Entre 1994 y 1997 será profesor visitante de la Flacso México, en donde impartirá un seminario sobre subjetividad y política. De regreso a Chile, trabajará en la oficina del Programa de las Naciones Unidas para el Desarrollo (PNUD) en Santiago, en la elaboración de los "Informes sobre Desarrollo Humano".

Lechner publicó once libros. Los volúmenes compilados son: Estado y política en América Latina (1981), ¿Qué significa hacer politica? (1982), ¿Qué es el realismo en política? (1987), Cultura politica y democratización (1987), Capitalismo, democracia y reformas (1990) y (en colaboración con René Millán Valenzuela y Francisco Valdés Ugalde) Reformas del Estado y coordinación social (1999). Los de autoría propia incluyen: La democracia en Chile (1970), La crisis del Estado en América Latina (1977), La conflictiva y nunca acabada construcción del orden deseado (1984), Los patios interiores de la democracia. Subjetividad y politica (1988) y Las Sombras del Mañana. La dimensión subjetiva de la politica (2002).

En agosto de 2003 el Parlamento chileno le otorgó la ciudadanía por gracia. Falleció en Santiago de Chile en febrero de 2004.

Sin ánimo de introducir un esquema rígido podríamos hablar de tres periodos en el decurso de su obra. Cada uno de ellos definido por la aparición de sus trabajos más importantes, pero atravesados por dos cortes funda- 
mentales que inducirán a la exploración de nuevos "marcos de referencia": la llegada a América Latina (en particular su primera residencia en Chile) y luego la experiencia del golpe de Pinochet. Claro que este esquema no debe ser entendido como la delimitación de compartimentos aislados, sino más bien estos segmentos se solapan en un derrotero vital, político e intelectual de constantes búsquedas.

El primer periodo de formación se extiende desde su ingreso a la carrera de Derecho (1964) y su posterior reorientación al estudio de la ciencia política, que culmina con la presentación de su tesis doctoral en 1969: El proceso de democratización en Chile. Un intento de interpretación del desarrollo politico. La tesis encarna - según su valoración autocrítica- "un enfoque ecléctico, sin mayor brillo", en el que se combinan los enfoques predominantes en la enseńanza de la ciencia política alemana de la época, derivados de la escuela norteamericana del desarrollo político o de la teoría sistémica de David Easton, junto con una mirada tomada de la obra de Ralf Dahrendorf que le permite tematizar algunas cuestiones clave: "la dinámica del cambio social, el conflicto de clases, la democracia como institucionalización de conflictos" (Lechner, 2004).

Un segundo periodo de transición abarca desde la publicación de la "traducción” al castellano de su tesis, bajo el título La democracia en Chile (1970), hasta su libro de 1984. Las diferencias entre su tesis alemana (281 pp.) y el libro publicado en Argentina ("una versión reducida de la tesis de doctorado" de 173 pp.), son lo suficientemente significativas como para considerar esta última publicación como parte de una etapa diferente. En particular cabe destacar que Lechner no solo expurga al texto español de múltiples referencias locales (imprescindibles para una lectura alemana); lo más importante es que también elimina la introducción del texto alemán y la reemplaza por una nueva "Introducción a los prejuicios del autor", donde toma una fuerte distancia crítica con buena parte de los supuestos teóricos y metodológicos de su formación politológica anterior. Especialmente pondrá en discusión la visión heredada de su antiguo maestro, Dieter Oberndörfer, sobre el concepto de política como ciencia práctica, al que opondrá ahora sus nuevas convicciones en el sentido de que "una ciencia política que tiende a la transformación del mundo, sólo puede comprenderse como praxis revolucionaria, o sea como teoría de la emancipación" (Lechner, 1970: p. 12). ${ }^{4}$

4 Con los años, Lechner revisará a su vez estas posiciones y recompondrá su relación —académica y personal - con quien fuera su director de tesis doctoral. Agradecemos en este punto el testimonio del Dr. Nikolaus Werz, ex investigador del Arnold-Bergstraesser-Institut en Friburgo y actualmente en la Universidad de Rostock, quien mantuvo un trato personal con ambos colegas (La Plata, Argentina, septiembre de 2013). 
Ahora bien, este segundo periodo podría describirse como conformado por dos fases diferentes dentro del mismo itinerario. Un primer movimiento abarca el proceso de intenso involucramiento con el pensamiento marxista acompañado de un creciente compromiso político, que comenzó con la llegada de Lechner a América Latina. En esas circunstancias se forja un fuerte vínculo de intercambio con un conjunto de intelectuales de izquierda, entre los que se destaca su estrecha amistad y su diálogo intelectual con Franz Hinkelammert, pero también con los "gramscianos argentinos" (José Aricó y Juan Carlos Portantiero) y otros científicos sociales de la región. A su retorno a Alemania participa activamente del movimiento estudiantil, además de leer ávidamente a los pensadores del 68 . Según su testimonio: "yo ahí me formo en el ambiente — digamos— entre una formación 'formal' norteamericana y luego una formación 'informal' del '68, que es una mezcla de todos los textos piratas de Adorno, de Lukács, algo de Marx, Wilhem Reich. Todos los autores del '68, y también estaban los franceses, como Lucien Goldmann" (Lechner, 1988). Con ese bagaje a cuestas decide finalmente regresar a Chile. Como lo referirá el propio Lechner en un debate de 1971, al cotejar las diferencias entre la investigación que lo llevó a redactar su tesis y la visión teórica y política del momento:

Cuando llego a Chile en 1965, recibo el impacto de lo que significa "tercer mundo" y subdesarrollo. Vivo el apogeo y el desencantamiento de la "Revolución en Libertad". Mi formación estructural-funcionalista no me permite conceptualizar esta experiencia. Comienzo a estudiar a Marx y de regreso a Alemania participo en el movimiento estudiantil (1967-1969). Partiendo del análisis de la economía política llegamos a plantearnos: ¿Por qué el sistema capitalista no explota en sus contradicciones? (Lechner, 1971: p. 260).

Pero este mismo periodo, cortado brutalmente por el golpe de Pinochet, albergará un segundo movimiento en el pensamiento de Lechner, en este caso de "refocalización" crítica del marxismo - aunque no de los ideales socialistas que mantendrá desde su juventud - y que comienza a operarse a mediados de los ańos setenta. En tal sentido, tal vez haya que considerar La crisis del Estado en América Latina, libro publicado en Caracas en 1977, como su última publicación de envergadura plenamente inserta en una matriz teórica que en algunos puntos fundamentales comenzará a ser puesta en cuestión. ${ }^{5}$ Como dirá en la introducción del texto, presentado apenas como "un conjunto de apuntes para una teoría del Estado en América Latina”:

5 En ese año aparece la primera mención que registramos de Lechner sobre la obra de Arendt (Lechner, 2012: p. 495). 
Las presentes notas son tributarias del pensamiento marxista, especialmente de las corrientes representadas, entre otros, por Gramsci, Luxemburgo, Bloch y la Escuela de Fráncfort. Esta tradición se refleja en el interés práctico que guía el conocimiento y sus puntos de referencia. Mi preocupación por la praxis, la totalidad, la subjetividad, la revolución o la utopía, para nombrar algunos hitos de la reflexión, remite a aquel trasfondo político-teórico (Lechner, 2012: p. 358).

De este modo, el volumen se inscribe claramente en un linaje del "marxismo occidental" - para utilizar la fórmula de Perry Anderson- del que Lechner jamás renegará, pero que someterá a un considerable escrutinio crítico en los años por venir. Esa "refocalización" teórica, a su vez, irá de la mano de un desplazamiento hacia algunas preocupaciones que hasta ese momento habían ocupado un lugar lateral en su producción. Al recordar este periplo en su última conversación el autor germano-chileno señalará:

En los primeros ańos post-golpe intento tematizar la dictadura de Pinochet a partir de mi línea de trabajo anterior. Reúno tres artículos en torno a La crisis del Estado en América Latina (1977) y preparo una antología con cierto éxito editorial, Estado y politica en América Latina (1981). Sin embargo, estoy cada vez menos satisfecho con un enfoque estructural de la vida social. ¿Cómo dar cuenta de las experiencias subjetivas de la gente? Mi propia contribución a la antología ya explora nuevos campos (antropología política) buscando una nueva mirada sobre el Estado (2004: p. 23).

En efecto, por aquellos años Lechner comienza a forjar una mirada innovadora y polémica de las relaciones entre Estado y política respecto de "aquel trasfondo político-teórico” del que había partido. En febrero de 1980 presenta su ponencia "Aparato de Estado y forma de Estado" en el seminario "Hegemonía y alternativas políticas en América Latina”, realizado en Morelia, México (Labastida, 1985). De ese trabajo seminal vale citar un largo parágrafo:

La visión técnico-administrativa que encontramos en Marx - y que da lugar a los malentendidos economicistas - es la consecuencia de su énfasis en el trabajo como principal categoría de mediación entre los hombres. Su intuición inicial del trabajo gira en torno al metabolismo del hombre con la naturaleza, o sea lo que Hannah Arendt especifica como la labor impuesta por el siempre repetido ciclo de la vida biológica. Marx define al hombre como animal laborans, que se distingue de los animales por producir sus medios de subsistencia, y como homo faber, que a diferencia de los animales imagina el objeto a construir. Se refiere pues, en los términos de Arendt, a la labor y al trabajo, pero no a la acción. No considera 
suficientemente entre las actividades humanas a la interacción que se desarrolla entre los hombres por el simple hecho de existir hombres (y no el Hombre). El hombre qua hombre, dice Hannah Arendt, cada individuo en su única distinción aparece y se confirma a sí mismo en el discurso y la acción, y estas actividades -la política - necesitan un espacio para aparecer: el ámbito público, el estado. Éstos son mucho más "el trabajo del hombre" que la obra de sus manos o la labor de su cuerpo. Al concebir el trabajo en términos demasiado estrechos, Marx no logra situar la actividad política. De ahí el paradojal silencio sobre el "reino de la libertad". La emancipación humana del "trabajo impuesto por la necesidad y por la coacción de los fines externos" es abordada solamente en términos de "tiempo libre" (una libertad improductiva) y no de praxis social. Es decir, la socialización culmina en una extraña libertad de satisfacción privada-particular y no en la liberación de una reciprocidad espontánea (Lechner, 1985: p. 105).

Este "reduccionismo", como lo llama Lechner, es a su vez una lejana herencia hegeliana que se prolongará a través de múltiples ramificaciones en el pensamiento político progresista. Por eso, dirá en la "Introducción" de 1981 a la antología sobre Estado y política en América Latina, que "no se trata solamente de la aversión autoritaria contra la 'democracia de negociación' (Hayek). También encontramos en la izquierda un menosprecio por la actividad politica". Y volviendo a citar a Arendt señalará que la práctica política, "más que un medio para un fin, es un 'fin en sí mismo' en tanto afirmación del sujeto”. De aquí que hacer política no es "un 'plus' con respecto a otra actividad 'básica', sino la relación propiamente social en que los hombres se reconocen entre sí en tanto sujetos" (Lechner, 1988: p. 23. Cursivas nuestras).

En el marco de estas consideraciones, en el epílogo que escribe para la mencionada antología, marcará diversos adeudos que los tradicionales enfoques "estructurales" sobre el vínculo entre Estado y sociedad acarrean como un lastre y que dificultan pensar los desafíos políticos que atraviesan la región. Invertidos como un guante, cada uno de estos débitos se convertirán en objetos medulares de su reflexión posterior. Así, justificará la "necesidad política de una teoría del Estado en la necesidad de "hacer política", y nos dirá que "hacer política es devenir sujeto", por tanto, en el fondo, "la teoría del Estado trata pues de nuestro interés y voluntad colectiva por determinar nuestro modo de vida, el sentido de la convivencia social" (Lechner, 1988: p. 301). Esta creciente centralidad analítica de los problemas de la subjetividad lo llevará a afirmar que "la constitución de los sujetos es quizá el tema central de una teoría política. No obstante, suele ser desplazado a los supuestos antropológicos sobre los que se apoyan — sin problematizarlos - los distintos enfoques" (Lechner, 1988: pp. 325-326). A su vez, estas preocupaciones sobre los lazos entre subjetividad 
y (teoría) política establecerán los puentes —esbozados hacia el final del texto- - con una problemática que concitará toda su atención a partir de entonces:

[...] la situación latinoamericana nos plantea con urgencia un tema generalmente soslayado: la relación entre política y moral... [pero] en lugar de considerar a la moral como un juicio valorativo sobre una acción social, hemos de concebirla como un ordenamiento simbólico, intrínseco a toda práctica. Toda práctica social es $[\ldots]$ un proceso de producción y reproducción de sentido, que remite a la idea de un "buen orden" (Lechner, 1988: p. 331. Cursiva del autor).

Finalmente, un tercer periodo de madurez comenzará en los años ochenta con la publicación de La conflictiva y nunca acabada construcción del orden deseado (1984), y culminará con sus últimos trabajos en los albores del nuevo siglo. En esta última etapa la articulación de ejes analíticos conformada por sus reflexiones en torno a la subjetividad, la política y la democracia se afirmarán como una mirada privilegiada para pensar los problemas contemporáneos de la región. Como enfatizará Ilán Semo, "Lechner es uno de los precursores de la noción de subjetividad política en la ciencia política y la sociología latinoamericana". Así, mientras "todos en la academia están preocupados por los cambios institucionales, Lechner se enfoca en comprender el mundo de la subjetividad. Ésa es la riqueza de su pensamiento [...] es un teórico nodal de la subjetividad en la esfera de lo político". De acuerdo con esta visión, la teoría de la subjetividad política "replantea la manera en la cual se constituyen las relaciones entre el poder y el individuo, entendiendo la producción del sujeto singular, no el sujeto histórico". El foco de su reflexión se orienta a desentrañar "la subjetividad de lo que aparece objetivado, ésa es su tesis fuerte, de allí que sea tan profunda. Es una subjetividad del orden de lo simbólico" (Semo, 2014: p. 14. Cursivas nuestras).

\section{Lechner como lector de Arendt}

En los últimos años ha comenzado a desplegarse una creciente producción académica en torno a la obra de Norbert Lechner. Aunque todavía dispersa, esta bibliografía cubre distintos aspectos de su herencia intelectual, abre nuevos interrogantes y plantea sugerentes claves de aproximación. En principio, son de imprescindible lectura los estudios preliminares a las recientes ediciones de sus obras (Gutiérrez \& Moulián, 2006) y (Semo, Valdés \& Gutiérrez, 2012, 2013, 2014), los cuales presentan un amplio cuadro de interpretación, en el que es posible ubicar el itinerario biográfico del autor, entretejido con los avatares del 
contexto político e institucional en el que se desempeñó. Otras contribuciones, más cercanas al testimonio personal, han resaltado los legados de la producción de Lechner para las ciencias sociales latinoamericanas; entre ellas cabe destacar los textos de Emilio de Ípola (2004), Daniel García Delgado (2004), Rossana Reguillo (2004), Carlos Strasser (2004) y María Herminia Tavares de Almeida (2004). Asimismo, algunos trabajos ofrecen enriquecedoras miradas sobre diversas dimensiones de su obra: Acosta (1997), Rivas (2000), Burbano (2004), Guzmán (2007) y Jiménez (2012). Finalmente, en lo que nos interesa aquí, un grupo más pequeño de aportes ha puesto su atención sobre algunas "afinidades electivas" entre ciertos motivos de la producción de Lechner y el pensamiento de Hannah Arendt: Kohn (2000), Castillo (2008), Pressacco (2008), Caetano (2010) y Bacci (2014). Pero ninguno de estos trabajos ha ensayado hasta ahora una exploración sistemática de los "usos" que Lechner elabora, a partir de la reflexión arendtiana, en dirección a pensar los desafíos de la política democrática en América Latina.

Sin duda, sería descaminado etiquetar la obra de Lechner como "arendtiana”. Reacio a cualquier identificación de escuelas, él mismo se ha encargado de subrayarlo: "siempre he ido por caminos propios en cuanto a mi trabajo, nunca he sido de escuela, de pertenecer a una escuela determinada o seguir a un autor determinado, siempre he tratado de abrir mi propio camino" (Lechner,1988). Sin embargo, es claro también a partir de las pistas que el propio autor nos ha señalado, que los motivos del pensamiento de Arendt han sido especialmente gravitantes en la reorientación de su reflexión, en la elaboración de un nuevo "marco de referencia" y de un "nuevo estilo de exposición" para pensar la política. Este desplazamiento se hace especialmente patente en el conjunto de trabajos reunidos en su obra de 1984, que tanto para el autor, como para calificados observadores, constituye su "primera producción autónoma y original" (Gutiérrez \& Moulián, 2006: p. 10).

Aunque no podemos afirmarlo con certeza, podemos presumir que Lechner se acerca a la obra de Arendt por dos vías principales. Por un lado, por sus propias preocupaciones vitales, políticas e intelectuales que lo llevan a explorar nuevos senderos para pensar la sociedad y la política democrática a partir del quiebre autoritario. Como bien apunta Semo, la de Lechner es "una obra en la que hallaremos que lo que acontece en lo político se convierte en el territorio de una reflexión en la cual están contenidas todas las marcas y señales de lo que define al propio acontecimiento en su conjunto: los órdenes políticos generales, la cultura, la condición social”. Estamos así frente a un estilo de reflexión que no deriva sus problemáticas "de la marcha del pensamiento mismo (aislado), sino del cisma que el acontecimiento va produciendo en el mundo que hemos pensado" (Semo, 2014: p. 4). 
Pero por otra parte, también sus lecturas de la obra de Habermas (además de su contacto personal) han sido un puente privilegiado para acceder a la reflexión arendtiana. Como señaló alguna vez el autor de Conocimiento e interés, "a nadie le sorprenderá que en el ámbito de la teoría de la sociedad, sea de Alfred Schütz y de Hannah Arendt de quienes más he aprendido". Este aprendizaje toma cuerpo a través de tres aportaciones de fundamental importancia: "la reconstrucción del concepto aristotélico de 'praxis' para la teoría política", en segundo lugar "la introducción del concepto husserliano de 'mundo de la vidà en teoría de la sociedad", y finalmente, el "redescubrimiento de la Crítica del juicio de Kant para una teoría de la racionalidad". Mientras que el segundo aporte mencionado corresponde a Schütz, el primero y el tercero corresponden a Arendt, por lo que Habermas manifiesta sin rodeos: "de Hannah Arendt aprendí por dónde había que empezar una teoría de la acción comunicativa" (Habermas, 2000: pp. 356-358). ${ }^{6}$

Ahora bien, en el tránsito que va de una reflexión anclada en la "revolución" a una visión política centrada en la "democracia", la apropiación, adaptación y recreación de la obra de Hannah Arendt por parte de Lechner constituyó una significativa "refocalización" de su pensamiento. Esta lectura se articula en los tres planos ya señalados (Wallerstein, 1999): una visión de la política, un registro reflexivo que ensaya un camino original entre filosofía, ciencias sociales e incluso la literatura, y un modelo de intervención intelectual autónomo, que se separa tanto del militante de partido como del experto supuestamente "apolítico". En conjunto, estas contribuciones constituyeron un aporte original a las controversias sobre la transición democrática en América Latina.

\section{La política en cuestión}

En principio, la perspectiva arendtiana procura delimitar la especificidad de la política como una actividad que supone el reconocimiento de los otros como iguales pero al mismo tiempo el hecho de que cada individuo es singular. Dada esta condición básica de la pluralidad, la política resulta necesaria como forma de articulación y coordinación de los individuos. No hay entonces sujetos políticos dados, sino que en la actividad política misma se despliega la singularidad de cada quién a través de la acción y del discurso, al tiempo que se entreteje un horizonte de sentido compartido.

6 La primera vez que — según nuestro registro- Lechner cita a Arendt vincula su mirada en La condición humana con Teoria y praxis de Habermas (Lechner, 2012: p. 507). 
La pluralidad humana, básica condición tanto de la acción como del discurso, tiene el doble carácter de igualdad y distinción. Si los hombres no fueran iguales, no podrían entenderse ni planear y prever para el futuro las necesidades de los que llegarán después. Si los hombres no fuesen distintos, es decir, cada ser humano diferenciado de cualquier otro que exista, haya existido o existirá, no necesitarían el discurso ni la acción para entenderse. Signos y sonidos bastarían para comunicar las necesidades inmediatas e idénticas (Arendt, 2001a: p. 200).

De esta forma, al situar la pluralidad como foco de su reflexión política, Arendt lleva a cabo un descentramiento del sujeto político monolítico y singular, y en su lugar encontramos diversos y múltiples "sujetos" que se forjan en la interacción propia de la arena política (Di Pego, 2012). Lechner recupera explícitamente este papel de la pluralidad como pilar para la resignificación de la política:

¿Cómo pensar la política sin referencia al proceso de subjetivación? Una inspiración muy fecunda me ofreció Hannah Arendt, especialmente en La condición humana. Constatando que "los hombres, no el Hombre, viven en la tierra y habitan en el mundo", Arendt afirma que "esta pluralidad es específicamente la condición —no la conditio sine qua non, sino la conditio per quam - de toda vida política”. Es en relación a esa pluralidad de los hombres o (entendiéndolo como un proceso) esa pluralidad de sujetos que la construcción del orden político deviene tema central (Lechner, 1984: p. 21).

En la medida en que la pluralidad se erige en la condición que hace posible la política, esta siempre supone la reunión y la interacción de los hombres y mujeres para el tratamiento de los asuntos públicos. En este contexto, la democracia es el marco necesario, aunque no suficiente, para el despliegue de la política entendida como pluralidad. Por eso, Arendt sostiene que "el conjunto de argumentos contra la 'democracia' [...] cuanto más consistente y razonado sea, se convierte en alegato contra la esencia de la política” (2001a: p. 241). La democracia obra como el ordenamiento legal que hace posible la interacción, el disenso y la disputa en un marco de conflictividad en el que los otros no dejan de reconocerse como sujetos de derecho. Sin embargo, la política además de sustentarse en la pluralidad remite para Arendt a la posibilidad de introducir novedad en el mundo y de actuar de manera inesperada. "[...] la acción mantiene la más estrecha relación con la condición humana de la natalidad; el nuevo comienzo inherente al nacimiento se deja sentir en el mundo sólo porque el recién llegado posee la capacidad de empezar algo nuevo, es decir, de actuar" (Arendt, 2001a: p. 23). 
Por eso la política requiere de un marco institucional que le otorgue estabilidad, pero no puede reducirse a la mera reproducción de lo establecido. En particular, Arendt destaca el papel de las leyes en tanto que posibilitan la interacción entre iguales en el espacio público, y al mismo tiempo lo dotan de cierta perdurabilidad, sin la cual el espacio público se encontraría en un estado precario y en constante peligro de desaparecer. En La condición humana, Arendt se detiene especialmente en la polis griega para mostrar de qué manera la ley obraba como una muralla que delimitaba y hacía posible la vida política.

La ley de la ciudad-estado [...] literalmente era una muralla, sin la que podría haber habido un conjunto de casas, una ciudad (asty), pero no una comunidad política. Esta ley-muralla era sagrada, pero sólo el recinto era político. Sin ella, la esfera pública pudiera no tener más existencia que la de una propiedad sin valla circundante; la primera incluía la vida política, la segunda protegía el proceso biológico de la vida familiar (Arendt, 2001a: p. 71).

Pero también en la época moderna la política requiere de un cierto ordenamiento legal que no se limita al reconocimiento de derechos sino que actúa como un muro de contención de los asuntos humanos (Canovan, 2000: p. 22). En otras palabras, para el despliegue de la política resulta necesario un ordenamiento legal e institucional que asegure la permanencia y la estabilidad del espacio público de interacción entre iguales. En Sobre la revolución, Arendt advierte que esta fue precisamente la tarea que emprendieron, sin mayor éxito, los revolucionarios del siglo XVIII, a quienes

[...] aún les parecía natural la necesidad de una constitución que fijase los límites de la nueva esfera política y definiese las reglas que la gobernasen, así como la necesidad de fundar y constituir un nuevo espacio político donde las generaciones futuras pudiesen ejercitar sin cortapisas la "pasión por la libertad pública" o la "búsqueda de la felicidad pública" [...] que consistía en el derecho que tiene el ciudadano a acceder a la esfera pública (Arendt, 1992: pp. 125-127).

La política se encuentra así atravesada por una tensión constitutiva entre las leyes y las instituciones que establecen un orden determinado y la irrupción de la novedad y el carácter agonístico que la acción plural trae consigo. Pero esta tensión no debe concebirse como una oposición irreconciliable entre elementos contrapuestos, sino como elementos en cuya dinámica de interacción en conflicto se constituye lo político (Di Pego, 2006). De manera que la conflictividad resulta no solo dinamizadora sino también inherente al orden establecido. En palabras de Lechner (1984: p. 151): "Hay una diver- 
sidad propia a todo ordenamiento social que pone límites a la pretensión de eliminar los conflictos".

Lo que ha sucedido es que en la tradición del pensamiento político se ha escindido esta articulación entre la perdurabilidad de lo instituido y la irrupción de la novedad, produciéndose en consecuencia un vaciamiento de la conflictividad de la política. Esta escisión entre novedad y estabilidad también se encuentra en la base de nuestro vocabulario político moderno, "que se presenta siempre en pares de conceptos opuestos: derecha e izquierda, reaccionario y progresista, conservadurismo y liberalismo" (Arendt 1992: p. 231). Frente a esto, Arendt explicita su ímpetu por volver a los conceptos políticos, para desmantelar las oposiciones y pensarlos nuevamente en su entramado conflictivo constitutivo: "Desde el punto de vista filológico, el esfuerzo que se realiza para reconquistar el espíritu perdido de la revolución, debe consistir, en buena parte, en repensar y combinar de modo significativo todo lo que nuestro vocabulario político nos ofrece en términos de oposición y contradicción" (Arendt, 1992: p. 231).

La política así concebida implica un doble desplazamiento desde la centralidad del sujeto hacia la pluralidad y desde una lógica estratégica hacia una dinámica de interacción agonal de construcción de sentido compartido que excede al funcionamiento de las instituciones políticas establecidas. De ahí la relevancia del espacio público como ámbito de reunión en el que los asuntos comunes se resuelven a través del diálogo y la persuasión entre iguales.

Diversos regímenes han procurado erradicar el espacio público y su conflictividad propia, para lo cual resulta asimismo necesario, eliminar la pluralidad. Así, el totalitarismo se vuelve en Arendt la contracara para pensar la política en este sentido específico que resulta suprimido en diversas formas de dominación — totalitarismo, dictadura, autoritarismo- De manera análoga a como Arendt elabora su concepción política a partir del contraste con el totalitarismo, Lechner también lleva a cabo una reconceptualización de la política a partir de la experiencia de la dictadura en Chile. En esta tarea, Lechner recupera los análisis arendtianos de la política en su íntimo vínculo con la pluralidad y el espacio público, al tiempo que encuentra en la negación de estas características, dos de los pilares básicos del autoritarismo: la expulsión de los ciudadanos del espacio público y la sustracción de derechos fundamentales a sectores enteros de la población - y por tanto la negación de la pluralidad entendida en su doble faceta de igualdad y distinción.

La privatización es un sostén para la existencia de un régimen autoritario, pero a la vez una barrera para su desarrollo. La gente se retira de un espacio público vaciado de contenido colectivo; repliegue a la familia y unas pocas amistades como refugio de emergencia. Se trata de una fuga en términos literales, pero también de 
una fuga de sentido: ya no se invierte sentido en la vida pública. ¿Qué pasa con los afectos recluidos al fuero íntimo? Lo que comienza como una hibernación puede terminar como una mutilación. Se cortan los lazos con el pasado, pero sin por eso apostar al futuro. Si el ayer aparece como tiempo perdido, el mañana es inimaginable... Este ensimismamiento en el presente fortalece el orden fáctico en tanto reduce lo real a la existencia tangible. Solamente lo inmediatamente dado ofrece seguridad. Y sólo se invierten esperanzas en el aquí y ahora. [...] Sin perspectiva que trascienda el presente, el orden solamente representa continuidad hacia atrás (por lo que ha durado). Dura día a día, pero no proyecta continuidad a futuro. ¿Qué sentido puede motivar un orden que no trasciende la existencia individual, quitándole su futilidad? (Lechner, 1984: p. 150).

Al finalizar el párrafo precedente, Lechner (2001a: p. 64) cita en una nota al pie la siguiente afirmación de La condición humana sobre el espacio público: "Si el mundo ha de incluir un espacio público, no se puede establecerlo para una generación y planearlo sólo para los vivos, sino que debe superar el tiempo vital de los hombres mortales. Sin esta trascendencia en una potencial inmortalidad terrena, ninguna política, estrictamente hablando, ningún mundo común ni esfera pública resultan posibles".

La restricción del espacio público no supone solamente una erosión de las posibilidades de expresión sino también del sentido compartido que se extiende hacia el pasado y el futuro obrando a la vez como simiente de la política y puente entre las generaciones. Así, la política en lugar de concebirse como un medio para un fin determinado, se presenta como un ámbito en donde se forjan y disputan los sentidos compartidos que sustentan a las instituciones y al ordenamiento social en general. Cuando los regímenes autoritarios obligan a los ciudadanos a replegarse en el ámbito privado, cercenan de ese modo la pluralidad constitutiva del espacio público y con ello erosionan las bases mismas de la política. En este contexto, Lechner advierte que, "como dice Hannah Arendt, vivir una vida privada por completo significa por encima de todo estar privado de ver y de oír a los demás, de verse y oírse a sí mismo" (1984: p. 156).

Pero una vez restringido o incluso erradicado el espacio público bajo ciertas formas de dominación, pueden subsistir ciertas manifestaciones de la pluralidad. Por eso, en el transcurso del siglo xx, las formas de dominación se han radicalizado hasta despojar a los individuos de todo tipo de derecho, inclusive del derecho más básico y fundamental que Arendt denomina "el derecho a tener derechos" (1999: p. 375), esto es, a pertenecer a "una comunidad que quiera y pueda garantizar cualesquiera derechos. El Hombre, así, puede perder todos los Derechos del Hombre sin perder su [...] dignidad humana. Sólo la pérdida de la comunidad misma le arroja de la Humanidad" (1999: p. 376). Cuando no 
hay ningún Estado dispuesto a reconocer a un grupo de individuos como sujetos de derecho, ni siquiera para oprimirlos, entonces se vuelven superfluos y en el momento en que son expulsados de la comunidad política, quedan fuera de la ley y sujetos a la completa arbitrariedad por parte de los poderes establecidos. Lechner remite a la negación del "derecho a tener derechos" en relación con el golpe de 1973 en Chile, citando al final del siguiente párrafo un artículo de Arendt que apareció originariamente en 1949 en Alemania (Die Wandlung 4, pp. 754-770) denominado: "Es gibt nur ein einziges Menschenrecht" ("Existe solo un único derecho humano"): "En nombre de la unidad se excluye lo diferente. El otro (el enemigo) es expulsado del orden. No tiene 'derecho al Derecho'. Sin ley, ni rey, es expoliado de su Derecho Humano fundamental — su pertenencia a una comunidad política por medio de la cual el hombre privado accede a aparecer en público: ser sujeto" (Lechner, 1984: p. 146). ${ }^{7}$

El autoritarismo lleva a cabo así una doble ruptura de la trama de sentido que sustenta a la política, por un lado, al cercenar el espacio público recluyendo a los individuos en el ámbito privado, y por otro, al expulsar y eliminar a grupos enteros de individuos de la comunidad política. Por eso, la perspectiva arendtiana se vuelve tan gravitante en el pensamiento de Lechner para una reinterpretación de la política, en la medida en que brinda elementos para la reconstrucción del sentido compartido erosionado por las formas de dominación autoritarias. El "derecho a tener derechos" entendido como un derecho humano fundamental, se erige en el sostén ineludible de todo régimen democrático, que además requiere la consolidación y expansión de espacios públicos en los que se diriman los legados del pasado y las proyecciones futuras. De este modo, el examen crítico de las derivas autoritarias constituye el contrapunto para la reinterpretación de la política.

\section{Un registro original}

Pero los puntos de convergencia entre la obra arendtiana y el pensamiento de Lechner no se limitan a significativas coincidencias de "contenido". También encontramos notorios puntos de contacto en lo que hace al registro expositivo, donde ambos se mueven en un "espacio controversial" que rechaza rígidos encuadramientos disciplinares. Así, en el epígrafe que abre este trabajo Lechner advierte la relevancia que tuvo la lectura de La condición humana después del golpe, aclarando inmediatamente: "No sólo por su contenido, también por

Lechner anticipó esta discusión en dos trabajos de 1980 (Lechner, 2013: pp. 43-76) y de 1983 (Lechner, 2013: pp. 247-257). Véase Bacci (2014). 
su estilo de exposición" (Cursivas del autor). En tal sentido, Arendt se mueve en un registro reflexivo que resulta difícilmente encasillable, que mantiene sus reservas respecto de la tradición filosófica y de las ciencias sociales, aunque se despliega a partir del diálogo y la confrontación crítica con ambas.

Respecto de la filosofía, Arendt objeta la tendencia a concebir esta actividad como un retiro del mundo, que la pone a resguardo de sus vicisitudes, y culmina haciéndola perderse "en las nubes de la pura especulación" (2005: p. 378). Asimismo, la filosofía se encuentra marcada en sus orígenes por la condena a muerte de Sócrates por parte de la polis ateniense (Arendt, 2001a: p. 25), a partir de lo cual la principal inquietud de Platón será poner a resguardo a la actividad filosófica de los avatares de los asuntos humanos, y pensar una forma de gobierno en la que esta actividad pueda ser desarrollada libremente. Consecuentemente la filosofía surge signada por la desconfianza hacia la pluralidad y la búsqueda de trascenderla con criterios capaces de sustraerse de la opinión compartida (Arendt, 2008: pp. 43-75). En la medida en que la filosofía se erige en conflicto con la política, Arendt considera que plantear una "filosofía política" constituye una contradicción en sus términos. Por eso, como es ampliamente conocido, rechaza ser denominada filósofa. Como lo destacó en una entrevista que Günther Gaus le realiza en 1964: "Yo no pertenezco al círculo de los filósofos. Mi profesión, si puede hablarse de algo así, es la teoría política" (2005: p. 17).

Arendt caracteriza, entonces, su propia actividad como teoría política, y esta se distingue de la filosofía pero también de las ciencias sociales. En relación con estas últimas, Arendt se posiciona críticamente en cuanto al paradigma cientificista imperante en la posguerra, que tendía a "concebir una 'ciencia de la sociedad', como disciplina omniabarcadora, [...] que compartiría los mismos patrones científicos de la ciencia natural y procedería de acuerdo con ellos" (Arendt, 2005: p. 456). En este sentido, Arendt caracteriza su actividad en relación con la comprensión (Verstehen), distinguiéndola claramente de los procedimientos y patrones de precisión científica dominantes en las ciencias sociales. De este modo, Arendt aguijonea a las ciencias sociales con el espíritu filosófico, al mismo tiempo que resitúa a la filosofía en el mundo vinculándola a las experiencias políticas fundamentales de nuestro tiempo (Di Pego, 2015).

En este entrecruzamiento de filosofía y ciencias sociales que da lugar a un registro singular, también la literatura constituye un insumo fundamental. En Los origenes del totalitarismo, encontramos diversos motivos literarios de los que Arendt se sirve para el análisis de cuestiones sociales y políticas. Así, por mencionar algunos de los casos más destacados, Arendt (1999: pp. 133-279) se detiene en la obra de Proust, En busca del tiempo perdido, para dar cuenta de la emergencia de una forma específica de antisemitismo en Francia. El corazón de 
las tinieblas de Conrad le permite analizar la visión de los colonos europeos en África que ilustra el devenir de la barbarie inherente a la civilización occidental (p. 256). En las historias de Kipling encuentra la construcción acabada de la "leyenda imperialista" (pp. 277-279) que pretende justificar a través de hazañas y actos legendarios el establecimiento de las colonias británicas. También encontramos diversas referencias a obras de Brecht, El vuelo de Lindbergh (1999: p. 414) y La ópera de los tres centavos (1999: p. 417); de Sartre, A puerta cerrada (1999: p. 414), y de Camus (1999: p. 549). Kafka se hace presente en relación con el funcionamiento de la burocracia austríaca (1999: p. 319), pero también reaparece en otros libros cardinales de Arendt como La condición humana (2001a: pp. 277, 346-347) y Entre el pasado y el futuro (1996: pp. 15-20).

La referencia a la literatura no es meramente ejemplificadora sino que constituye una herramienta de pensamiento, en la medida en que aporta una mirada aguda y penetrante de la realidad social. Incluso podría decirse que en esta aproximación a la literatura se constituye una modalidad particular de pensamiento, que Arendt denomina pensamiento poético [dichterisch Denken] (2001b: p. 174). Así, nos advierte que ciertos "factores sociales, que no son tenidos en cuenta en la historia política o en la económica, ocultos bajo la superficie de los acontecimientos, jamás percibidos por el historiador", resultan no obstante "registrados [...] por la fuerza más penetrante y apasionada de poetas y novelistas (hombres a quienes la sociedad había impulsado a la desesperada soledad y al aislamiento de la apologia pro vita sua)" (1999: p. 141). Con palabras muy similares y nombres propios en común, se refiere Norbert Lechner, en lo que sería su última entrevista, al papel que la literatura desempeñó en su trayectoria intelectual para la comprensión de la realidad frente a ciertas restricciones de las ciencias sociales: "Como muchos de mi generación tengo a Camus y Sartre, Brecht y Kafka como autores de cabecera. Estoy convencido de que muchas veces se aprende más de la realidad por medio de la literatura que a través de las ciencias sociales" (Lechner, 2004).

Este cruce de registros donde la "objetividad" del análisis se entrecruza con la "subjetividad" de la experiencia en primera persona aparecerá en numerosos trabajos de Lechner a partir de la década de 1980. De este modo, la apelación a la subjetivación como proceso no solo será un tema de reflexión, sino también permeará el modo de argumentación en que los problemas son expuestos, ya que en muchos trabajos la entrada en materia proviene de referencias tomadas de la literatura universal (valga como ejemplo la figura de Antígona en un artículo de 1981, "Acerca de la Razón del Estado"), o bien de vivencias cotidianas capaces de ilustrar situaciones sociales o políticas a mayor escala. En este último caso, por ejemplo, el capítulo II de La conflictiva... se entreteje en torno a las derivas de una pelea por obtener un lugar en las hamacas de un 
barco, o el capítulo III, que comienza con una sugerente reflexión sobre los juegos de información entre los niños (Lechner, 1984). Podríamos afirmar, sin equivocarnos por mucho, que este estilo de exposición constituía una verdadera y atractiva rareza frente a las modalidades de escritura comunes en las ciencias sociales latinoamericanas de la época. ${ }^{8}$

Sin duda, esta fuerte inclinación por la expresión de la subjetividad tiene en Lechner raíces biográficas muy profundas, que van incluso mucho más allá de su frustrada vocación por estudiar bellas artes. En parte, se vinculan con la elaboración de un lugar propio en la historia familiar ("La literatura me sirvió para hacerme un espacio frente a la figura dominante — en términos normativos e intelectuales- de mi padre"), en parte también con la vivencia de un niño alemán criado en otro país:

Me parece que el bilingüismo puede acentuar las dificultades de un joven para desarrollar una identidad propia... Ahora pienso que esa debilidad del lenguaje materno debe influir igualmente en mi dificultad de recordar y verbalizar mis sueños... Yo pienso a partir de imágenes que por una u otra razón se cargan de significaciones preverbales que buscan expresarse en palabras escritas. En ese paso de la imaginación visual al pensamiento discursivo se juega para mí el trabajo intelectual (Lechner, 2004).

Pero estas búsquedas expresivas no terminaron de cuajar en una voz personal y reconocible hasta entrados los años ochenta, cuando fruto de la lectura de Arendt (y de Gramsci) Lechner encontró inspiradores espejos donde calibrar una escritura absolutamente original en el concierto de la filosofía, la sociología o la ciencia política en la región.

\section{La autonomía intelectual}

Por último, en relación con el tercer plano objeto de análisis, queremos dejar esbozado para un tratamiento futuro más profundo un sugestivo paralelismo: el pensamiento de Arendt como el de Lechner se caracterizan por un modo de intervención intelectual autónomo respecto de las escuelas y perspectivas contemporáneas pero que también mantiene ciertas reservas o distanciamiento de la política partidaria y de la lógica estatal. Al comienzo de este apartado,

8 Mientras Lechner elaboraba su obra de 1984 desarrollaba un proyecto sobre la "vida cotidiana en Chile", en el que se destacan las referencias al concepto de espacio público de Arendt (Lechner 2013: pp. 445 y ss.). 
hemos citado palabras de Lechner que manifiestan su afán por abrir su "propio camino" en lugar de ponerse bajo la égida de escuelas o pensadores reconocidos. Por su parte, en un debate en el marco de un congreso sobre "La obra de Hannah Arendt" en 1972, Hans Morganthau le pregunta a Arendt: "¿Qué es usted? ¿Es conservadora? ¿Es liberal? ¿Dónde se sitúa usted entre las perspectivas contemporáneas?”. A lo que ella responde:

No lo sé. Realmente no lo sé y no lo he sabido nunca. Supongo que nunca he tenido una posición de este tipo. Como saben, la izquierda piensa que soy conservadora y los conservadores algunas veces me consideran de izquierdas, disidente o Dios sabe qué. Y debo añadir que no me preocupo en lo más mínimo. No creo que este tipo de cosas arrojen luz alguna sobre las cuestiones realmente importantes de nuestro siglo (Arendt, 1998b: p. 167).

Arendt siempre enfatizó que quería comprender y esta tarea intelectual implica cierto distanciamiento que nos posibilita reconocer que "nuestro mundo común se ve siempre desde un número infinito de posiciones diferentes, a las que corresponden los más diversos puntos de vista" (1996: p. 59). De esta manera, actuar y comprender resultan inescindibles, pero la actividad intelectual debe tomar cierta distancia que sin desvincularla del mundo, le permita tener una mirada del "mismo mundo desde la posición del otro", en la que se aprenda "a ver lo mismo bajo aspectos muy distintos y, a menudo, opuestos" (Arendt, 1996: p. 60). Desde este modelo de intervención intelectual autónomo, Arendt se posiciona también críticamente respecto de los denominados "profesionales de la resolución de problemas" que "han llegado al Gobierno partiendo de las Universidades y de algunos "tanques de pensamiento", pertrechados algunos con las teorías de los juegos y los análisis de sistemas, preparados, pues, en su propia opinión, para resolver todos los "problemas»" (Arendt, 1998a: p. 17). Por su parte, Lechner advierte en los años ochenta, la confluencia en el caso chileno de militares y tecnócratas civiles en una tendencia a la reducción tecnocrática de la política, que contribuye al vaciamiento del espacio público y a la consecuente restricción de la pluralidad: "Los militares y los tecnócratas civiles comparten el mismo paradigma [...] Visto así, la política consiste en el conocimiento científico de la realidad social (la 'ciencia económica') y la adaptación de la voluntad a las necesidades. Se trataría pues de calcular las opciones implícitas a los procesos sociales para decidir en función de éstas el objetivo preferido" (Lechner, 1984: p. 151).

De este modo, retornamos así a la primera cuestión referida al paradigma de política que comparten Arendt y Lechner, puesto que en definitiva la misma actividad intelectual se encuentra delimitada y definida por esta concepción de 
la política. La reducción tecnocrática de la política se hace presente no solo en las esferas del Estado sino también en la delimitación de ciertos profesionales de la política. Por lo que una crítica de estas tendencias implica, como hemos visto, redefinir la concepción política misma tanto como la actividad intelectual que la sustenta.

\section{Reflexiones finales}

Como lo señalaran los editores argentinos de la revista Controversia, en su número de lanzamiento en octubre de 1979, escribiendo desde el exilio mexicano: "Muchos de nosotros pensamos, y lo decimos, que sufrimos una derrota, una derrota atroz. Derrota que no sólo es la consecuencia de la superioridad del enemigo sino de nuestra propia incapacidad para valorarlo, de la sobrevaloración de nuestras fuerzas, de nuestra manera de entender el país, de nuestra concepción de la política."

En una sintonía análoga, pero dando unos años después nuevas vueltas de tuerca sobre la cuestión, Lechner dirá: “Pensar la derrota” no es sólo revisar una estrategia de lucha, es interrogarnos acerca de la lucha misma y, por ende, redefinir el significado de la propia política. Visto así, la reflexión política en nuestros países me parece todavía demasiado cautelosa, como si temiéramos reconocernos vulnerables. Son estos miedos no asumidos o mal integrados a la vida los que provocan desaliento o desazón.” (Lechner, 1988: p. 15).

Hemos tratado de argumentar en este trabajo que en ese doloroso esfuerzo por pensar la política latinoamericana desde la "derrota" la obra de Hannah Arendt fue fundamental para la "refocalización" del pensamiento de Lechner, no solo por su contenido, también por su registro original de expresión y por la defensa de un modelo de intelectual autónomo.

Aunque en estas líneas finales tal vez valga la pena arriesgarse a conjeturar que las "afinidades electivas" entre ambos quizá trascienden el plano intelectual para hundir sus raíces en zonas más profundas, tal vez insondables, de sus respectivos itinerarios biográficos. No se trata solo de dos pensadores de origen alemán que escribieron gran parte de su obra en otra lengua, y que vivieron el mayor tiempo de su vida adulta en otro país, al que tomaron como patria de adopción. En gran medida, también su obra política es inescindible de la experiencia del autoritarismo, tanto el que recorrió Europa bajo la faz del totalitarismo nazi-fascista, como el que asoló América Latina encarnado en las dictaduras militares.

A su vez, los dos mantuvieron con Alemania — con su historia, su política, sus costumbres - una tensa relación que nunca disimularon; un vínculo que le 
debe tanto al desarraigo como a la identidad, a la distancia como a la cercanía, a la otredad como a la pertenencia. Arendt tuvo oportunidades de volver a su país, pero nunca lo hizo; y Lechner pudo irse de Chile, pero optó por quedarse.

Sin embargo, y pese a todas las diferencias, ambos permanecerán fieles a los hilos invisibles de ciertas tradiciones intelectuales y culturales de raíz germana; los dos encontrarán siempre inspiración en la literatura de Kafka o de Brecht; los dos mantendrán — desde el principio al final de sus días — un diálogo crítico constante con el pensamiento filosófico, político o social en su lengua materna. A fin de cuentas, a la vuelta de los años, quizá de ambos podría decirse lo que Arendt reconoció alguna vez de sí misma: Si en realidad "provengo de» alguna parte, es de la filosofía alemana.

\section{Referencias}

Acosta, Y. (1997, mayo-diciembre). El debate de la postmodernidad en América Latina. En torno a las posiciones de Franz Hinkelammert y Norbert Lechner. Revista Islas, (115), 43-49.

Adorno,T. et al. (1973). La disputa del positivismo en la sociología alemana. Barcelona: Grijalbo.

Alexander, J. (1989). Las teorías sociológicas desde la Segunda Guerra Mundial. Barcelona: Gedisa.

Arendt, H. (2008). La promesa de la política (2005). Barcelona: Paidós.

Arendt, H. (2006). Diario filosófico 1950-1973 (2002). Barcelona: Herder.

Arendt, H. (2005). Ensayos de comprensión 1930-1954 (1994). Madrid: Caparrós.

Arendt, H. (2001b). Hombres en tiempos de oscuridad (1968). Barcelona: Gedisa.

Arendt, H. (2001a). La condición humana (1958). Barcelona: Paidós.

Arendt, H. (1999). Los origenes del totalitarismo (1951). Madrid: Taurus.

Arendt, H. (1998a). Crisis de la República (1972). Madrid: Taurus.

Arendt, H. (1998b). De la historia a la acción (1995). Barcelona: Paidós.

Arendt, H. (1992). Sobre la revolución (1963). Buenos Aires: Siglo XXI.

Arendt, H. (1966). Entre el pasado y el futuro. Ocho ejercicios sobre la reflexión politica (1968). Barcelona: Península. 
Bacci, C. (2014). Afinidades electivas: lecturas intelectuales de Hannah Arendt en la Argentina de los años 80. Ponencia en las viı Jornadas de Trabajo sobre Historia Reciente, Bs. As., Facultad de Ciencias Sociales/UBA (mimeo).

Burbano de Lara, F .(2004). Las búsquedas de Norbert Lechner. Iconos, (19), 141-146.

Caetano, G. (2010, Enero-Diciembre). El Bicentenario como oportunidad: Teoría y agenda para nuevos balances y prospectos en América Latina. Estudios, (23-24), 51-72.

Camou, A. (2013, primavera, octubre-diciembre). ¿De la revolución a la democracia? Revisitando el debate académico sobre las transiciones en América Latina (1973-1983). Revista Questión, (40), 43-58.

Canovan, M. (2000). Hannah Arendt como pensadora conservadora. En Birulés, F. (Comp.). Hannah Arendt. El orgullo de pensar (pp. 51-75). Barcelona: Gedisa.

Castillo Gallardo, M. (2008). "Ya no Somos Nosotros": Identidades politicas en el Chile contemporáneo. Tesis de la Maestría en Ciencias Sociales. México: Flacso México.

De Ípola, E. (2004, mayo). Días aciagos. Anuario social y político de América Latina y el Caribe, (7), 15-16.

Di Pego, A. (2015). Politica y filosofía en Hannah Arendt. El camino desde la comprensión hacia el juicio. Buenos Aires: Biblos.

Di Pego, A. (2012). La revelación del «quién» en el mundo contemporáneo. Consideraciones a partir de las concepciones de Hannah Arendt y de Paul Ricoeur. Revista de Filosofía y Teoría Politica, (43), 45-78.

Di Pego, A. (2006). Poder, violencia y revolución en los escritos de Hannah Arendt. Argumentos. Estudios Críticos de la Sociedad, 19(52), 101-122.

García Delgado, D. (2004, mayo). El legado de Norbert Lechner. Anuario Social y Politico de América Latina y el Caribe, (7), 17-18.

Gutiérrez, P. \& Moulián, T. (2006). Prólogo. Obras Escogidas de Norbert Lechner (pp. 7-11). Santiago de Chile: Lom.

Guzmán, V. (2007). Norbert Lechner: Conversaciones a través del tiempo. Y a la distancia. Ponencia presentada en el seminario "Pensar lo real y lo (im)posible: la construcción del orden social. Actualidad del pensamiento de Norbert Lechner”, 14 y 15 de junio. Centro de Estudios de la Mujer. Santiago de Chile: Universidad Alberto Hurtado. 
Habermas, J. (2000). Perfiles filosóficos-politicos. Madrid: Taurus.

Habermas, J. (1986). Ciencia y técnica como ideología. Madrid: Tecnos.

Hinkelammert, F. (2012). Teología profana y pensamiento crítico: conversaciones con Frank Hinkelammert (Entrevista de Estela Fernández Nadal y Gustavo D. Silnik). Buenos Aires: cicCUS/CLACSO.

Jiménez B., W. (2012, junio). El concepto de política y sus implicaciones en la ética pública: reflexiones a partir de Carl Schmitt y Norbert Lechner. Revista del CLAD, (53), 215-238.

Kohn W., C. (2000). Solidaridad y poder comunicativo: La praxis de la libertad en la filosofía política de Hannah Arendt. Res Publica, (5), 73-92.

Labastida Martín del Campo, J. (1985). Hegemonía y alternativas politicas en América Latina (Seminario de Morelia. Febrero de 1980). México: IIs-unam/Siglo XXI.

Lechner, N. (2014). Obras. Tomo III (Edición de Gutiérrez, P., Semo, I. \&Valdés Ugalde, F.). México: Flacso México/FCE.

Lechner, N. (2013). Obras. Tomo II (Edición de Gutiérrez, P., Semo, I. \& Valdés Ugalde, F.). México: Flacso México/FCE.

Lechner, N. (2012). Obras. Tomo I (Edición de Gutiérrez, P., Semo, I. \& Valdés Ugalde, F.). México: Flacso México/FCE.

Lechner, N. (2006). Obras escogidas de Norbert Lechner. Santiago de Chile: Lom.

Lechner, N. (2004). Última conversación con Norbert Lechner. Las condiciones sociales del trabajo intelectual. Entrevista de Paulina Gutiérrez y Osmar González. Cuadernos del CENDES.

Lechner, N. (1993, abril). La democracia entre la utopía y el realismo. II Encuentro Internacional de Filosofía Política, Segovia.

Lechner, N. (1990). Los patios interiores de la democracia (1988). Santiago de Chile: FCE.

Lechner, N. (1985). Aparato de Estado y forma de Estado. En Labastida Martín del Campo, J. Hegemonia y alternativas politicas en América Latina (Seminario de Morelia. Febrero de 1980) (pp. 81-111). México: IIs-UnAm/Siglo XXI.

Lechner, N. (1984). La conflictiva y nunca acabada construcción del orden deseado. Santiago de Chile: Flacso Chile. 
Lechner, N. (1982). ¿Qué significa hacer política? Lima: DESCO.

Lechner, N. (1970). La democracia en Chile. Buenos Aires: Ediciones Signos.

Lechner, N., Millán V., R. \& Valdés Ugalde, F. (1999). Reforma del Estado y coordinación social. México: Plaza \& Valdés.

Lechner, N., Barros, L., Faletto, E., Duque, J. \& Reca, I. (1971, junio-diciembre). Debate sobre La democracia en Chile. Revista Latinoamericana de Ciencias Sociales, (1).

Nudler, O. (2009). Espacios controversiales. Hacia un modelo de cambio filosófico y científico. Buenos Aires: Miño \& Dávila.

Pressacco, C. F. (2008, Primavera-Verano). Política y utopía en América Latina: reflexiones a partir del aporte de Norbert Lechner. Revista Encrucijada Americana, 2(2), 1-17.

Reguillo, R. (2004, julio-diciembre). La sombra en el presente. JÓVENes, Revista de Estudios Sobre Juventud, 8(20), 6-8.

Rivas Leone, J. A. (2000, noviembre-diciembre). Repensar la democracia: Una lectura de Norbert Lechner. Nueva Sociedad, (170), 6-12.

Semo, I. (2014, marzo). Obras de Norbert Lechner: una mirada a la historia intelectual de América latina. Entrevista de Jairo Antonio López Pacheco. Relacso, (4), 1-14.

Semo, I., Valdés Ugalde, F. \& Gutiérrez, P. (2013). Introducción. En Lechner, N. Obras. Tomo II (pp. 9-20). México: Flacso México/FCE.

Semo, I., Valdés Ugalde, F. \& Gutiérrez, P. (2012). Introducción. En Lechner, N. Obras. Tomo I (pp. 9-20). México: Flacso México/FCE.

Strasser, C. (2004, mayo). Adiós a un gran pensador. Anuario Social y Politico de América Latina y el Caribe, (7), 19-20.

Tavares de Almeida, M. H. (2004, mayo). Norbert Lechner: a inesgotável capacidade de ser solidário. Anuario Social y Político de América Latina y el Caribe, (7), 21-22.

Wallerstein, I. (1999). El legado de la sociología, la promesa de la ciencia social. Caracas: Nueva Sociedad.

Recibido el 24 de abril de 2015. Aceptado el 19 de septiembre de 2015. 